\section{Consumers have a right to affordable genetic testing}

There is no good reason for people to have access to their personal genetic information only through medical experts, as Arthur Beaudet suggests (Nature 466, 816-817; 2010). Such tests provide an incentive for consumers to learn about genetics and to support genetics research, while encouraging them to make reasonably informed decisions about their health.

Consumers have a right to acquire affordable information about their genetic profile. Independent studies could verify the quality of the data gathered, and this could easily be done by product-review organizations such as the US-based

Consumers Union.

Regulating the quality of data interpretation would be harder, especially because data-inference models improve over time. Companies should explain that their models for interpreting genetic material are probabilistic and imperfect. They should also reference the studies used to generate these models and allow users to download the uninterpreted data.

Some companies warn consumers that they should not change their lifestyle if they learn they have a higher risk of a disease. But if a test indicates that a person's risk of developing heart disease is above average, they may exercise more and eat better. Is this any worse than changing your behaviour because your father died of heart disease?

Beaudet suggests that ancestry tests may be acceptable with limited regulation, but that using the same genetic material to infer health-related information should have medical approval. Why should one type of genetic test be acceptable and the other not? Consumers may make life-altering decisions based on that information in both cases, but the fear that this information will harm them is speculative.

Because some genetic tests may have to compete with less expensive, direct-to-consumer products, people calling for a ban on such tests should declare any competing financial interests. Christopher Kanan Department of Computer Science and Engineering, University of California, San Diego, La Jolla, California 92093, USA e-mail: ckanan@cs.ucsd.edu

\section{Misconduct: don't assume science is self-correcting}

Your Opinion pieces propose that research misconduct could be prevented either by financial incentives for teaching research integrity or by informal intervention (Nature 466, 436437 and 438-440; 2010). Weak regulations and admonitions are unlikely to deter a prospective fraudster, as they are easily dodged.

The complex, idiosyncratic and ephemeral nature of much research encourages misconduct. Most instances of cooked data go undetected. Formal accusations to institutional officials are undermined by risk-management policies that try to minimize evidence of misconduct. And reasoned suspicion of incredible published findings is countered by the tendency of journals and leaders in the field to promote spectacular results.

Spotting fraud in a publication depends on a chance finding of identical data in different experiments. Even blatant and extensive incidents - as in the case of plastic transistors (see E. S. Reich Plastic Fantastic Palgrave Macmillan; 2009) and of reactome chemistry (see J. Travis Science 327, 22-23; 2010) went undetected by colleagues, reviewers and journal editors.

To deal with research misconduct, we need to uncover the extent of the problem and the factors encouraging it. A common attitude is that misconduct is rare and has little impact because science is self-correcting. Such complacency produces an environment in which fraudsters can flourish.

Thomas P. Hettinger University of Connecticut Health Center, Farmington, Connecticut 06030, USA e-mail: thetting@neuron.uchc.edu

\section{Misconduct: don't penalize the honest majority of scientists}

\section{Sandra Titus and Xavier}

Bosch suggest that scientific misconduct will be solved by "mandatory and frequent" educational classes for all members of institutions that receive government research funding (Nature 466, 436-437; 2010). But it is far from clear that the behaviour of the research community has improved since these classes were introduced.

If a politician proposed to solve the nation's crime problem by preaching "mandatory and frequent" sermons on the Ten Commandments to the entire population, few of us would vote for him or her. Bad behaviour rarely happens through ignorance of the law or of the rules that govern research. It arises because of human frailty, and is a feature of every profession and all societies. Individuals are criminals or cheats because they believe that they will not be caught.

Most scientists are honest and well aware of the ethical rules of research. Those who are not - because of inexperience, say - could receive targeted education. But it is unfair and inefficient to penalize the honest and experienced majority by increasing the already onerous regulatory and compliance burden that cripples today's discovery process.

Instead, follow the way society deals with crime: improve detection procedures and punish the guilty. Honest scientists do not need further governmental assault on their morale.

John P. Moore Joan and Sanford I. Weill Medical College of Cornell University, 1300 York Avenue, New York 100654896, USA

e-mail:jpm2003@med.cornell.edu

\section{Proposals for surface- temperature databank now open for scrutiny}

Our plan to create a suite of surface-temperature data sets for analysis by the international climate community (Nature 465, 158-159; 2010) is now under way. In the interest of transparency, we announce the publication of 12 white papers that are available until 1 September for public comment through a moderated blog (www.surfacetemperatures.org).

These papers were solicited from across the scientific community - including statisticians and metrologists, who have not so far been strongly engaged in producing surfacetemperature data sets. They cover a wide range of subjects, from construction of the raw databank to creation and assessment of climate quality data sets, and span the process from original measurement to dissemination of societally relevant information.

We welcome specific, constructive input from anyone, regardless of their expertise. We aim to represent this feedback at an international workshop on 7-9 September (see go.nature. com/bci8Gs).

Peter Stott Met Office Hadley Centre, Fitzroy Road, Exeter EX13PB, UK e-mail: peter.stott@metoffice.gov.uk Peter Thorne Cooperative Institute for Climate and Satellites, Asheville, North Carolina 28803, USA

\section{Clarifying knowledge ownership in Europe's medicines initiative}

Research organizations have criticized the intellectualproperty policies of the Innovative 